\title{
Meningkatkan Aktivitas Belajar Bahasa Indonesia Melalui Model Pembelajaran Pertemuan Kelas Pada Kelas V SDN 3 Pekanbaru
}

\author{
Desriana Sovia ${ }^{1}$, Nursalim $^{2}$ \\ 1,2Program Studi Pendidikan Guru Madrasah Ibtidaiyah, Universitas Islam Negeri Sultan \\ Syarif Kasim \\ e-mail:soviadesriana@,gmail.com
}

\begin{abstract}
ABSTRAK. This study aims to describe the increase in studen learing activities on Indonesia language lessons through the application of learning models for class meetings in class V SDN 3 Pekanbaru. The study was mitivated by the low of students' activities at Indonesian Language subject. The problems ware caused by some factors : the teacher used Monotonous way in teaching, the students were diffuclt in understanding the Subject, the were shy in delivering their ideas, the students were playing With their friend in studying, the students did not focus on studying, and they have Low interest instudy. The formulation of study were whether the use class meeting Learning model increased learning activities of Indonesian language at the fifth Year students of state elementary school 3 Pekanbaru.The study was done into two cycles, the first cycle and the second cycle were done into one meeting. For the success of study the writer arranged the following stages namely: 1) the preparation of action, 2) the implementation of action, 3) observation, 4) reflection.The success of class meeting model was known on the improvement of students' learning activities in Indonesia language subject prior action at the first cycle and at the second cycle. Students' learnig activities at prior action was categorized "low" as the number of 59 was in the range 45-64 and the average was 58,9\%. At the first cycle students' learning activities was categorized "enough" as the score 66 was in the range 65-74 and the average was $66,1 \%$. At the second cycle students' learning activities was categorized "very good" because the number 89 was in the range of 85-100 and the average was $88.7 \%$. this means that class meeting learning model improved students' learning activities of Indonesia language at the fifth year students of state elementary school 3 Pekanbaru.
\end{abstract}

Kata kunci: Learning Activitites, Class Meeting Learning Model.

\section{PENDAHULUAN}

Pembelajaran Bahasa Indonesia umumnya telah digunakan bagi seluruh jenjang pendidikan, mulai dari sekolah dasar hingga perguruan tinggi. Hal ini dikarenakan Bahasa Indonesia merupakan salah satu mata pelajaran wajib bagi setiap jenjang pendidikan saat ini. Bahasa Indonesia juga salah satu mata pelajaran yang menjadi salah satu syarat wajib 
kelulusan dalam setiap jenjang pendidikan. Untuk itu, siswa dituntut harus menguasai mata pelajaran ini.

Sekolah merupakan tempat terjadinya proses pembelajaran yang mana guru dan siswa berinteraksi sebagai pendidik dan peserta didik. Seorang pendidik dituntut terampil agar dapat membangkitkan aktivitas belajar pada diri peserta didik. Sehingga siswa dapat memberikan tanggapan yang sempurna dari sesuatu yang dikerjakan dan juga dapat mengerti lebih jelas yang kemudian diharapkan siswa menjadi lebih rajin, tekun dan percaya pada diri sendiri

Seorang pendidik selalu mengharapkan agar peserta didiknya mampu untuk beraktivitas dengan baik didalam kelas, terutama dalam proses belajar mengajar berlangsung. Agar terciptanya aktivitas belajar dengan baik bukanlah sesuatu hal yang mudah dilakukan oleh guru. Seorang guru harus mampu merancang strategi, model, ataupun teknik dalam proses pembelajaran yang tepat dengan materi pelajaran yang akan diajarkan oleh guru tersebut. Setiap sekolah tentunya menginginkan hasil belajar Bahasa Indonesia yang optimal, itu bisa tercapai bila didukung oleh aktivitas belajar yang tinggi.

Mata pelajaran Bahasa Indonesia di sekolah dasar berisi bahan pelajaran untuk mengembangkan kemampuan berfikir dan merupakan keterampilan dasar penggunaan bahasa meliputi: mendengar, berbicara atau becerita, membaca dan menulis. Temuan hasil belajar Bahasa Indonesia mencakup kemampuan-kemampuan berfikir dengan kata-kata seperti memahami dan merangkai kata dan kalimat dengan baik. Pelajaran Bahasa Indonesia juga menunjukkan kemampuan senang membaca buku, bercerita atau mendongeng, senang berkomunikasi, berbicara, berdialog dan berdiskusi.

Berdasarkan hasil wawancara awal dengan guru bidang studi Bahasa Indonesia di SD Negeri 3 Pekanbaru, diperoleh keterangan bahwa masih rendahnya aktivitas siswa dalam berinteraksi guru mata pelajaran dan juga dengan siswa lainnya dalam pembelajaran di kelas. Hal ini dapat dilihat dari gejala-gejala kesulitan belajar yang dialami oleh anak didik ketika belajar Bahasa Indonesia, yaitu sebagai berikut: 1. Siswa terkesan sulit memahami materi yang disampaikan oleh guru di kelas, hal ini terlihat lebih dari 14 orang $(50 \%)$ siswa jarang menjawab pertanyaan yang diberi gurunya. Materi yang disampaikan oleh guru di dalam kelas, hanya 4-5 orang siswa yang belajar dengan antusias tinggi yaitu siswa yang sudah terbiasa dalam bertanya, menjawab dan member solusi. Hal ini disebabkan karena pembelajaran yang dilakukan guru monoton sehingga materi yang disampaikan tidak menarik perhatian siswa sehingga siswa tidak bersemangat untuk mengikuti pelajaran didalam kelas. 2. Siswa malu untuk mengemukakan pendapat didepan kelas, dikarenakan rasa takut penghakiman atau penilaian dari temannya di kelas. Hal ini terlihat dari observasi awal peneliti ke sekolah, lebih dari $60 \%$ atau 20 orang siswa enggan untuk mengemukakan pendapat meskipun telah di tunjuk oleh gurunya untuk berbicara. 3. Siswa keseringan bermain dengan teman sebangkunya di kelas, ketika guru sedang menerangkan. Hal ini terlihat ketika peneliti melakukan observasi awal ke sekolah. Terdapat 15 orang siswa $(55 \%)$ berbicara dan bersenda gurau saat pelajaran dimulai. 4 . Konsentrasi siswa kurang terfokus terhadap materi yang disampaikan oleh guru di kelas, akibatnya 4-5 orang siswa terlihat mengantuk saat guru menyampaikan pelajaran di kelas. Rendahnya kemauan siswa dalam mengikuti pelajaran Bahasa Indonesia. Hanya sedikit siswa yang bersemangat mengikuti pelajaran di kelas yaitu 5-6 orang. 
Untuk mengatasi permasalahan diatas, guru dituntut untuk mampu mencari solusi agar permasalahan tersebut dapat diatasi. Salah satu kemampuan guru yang diungkapkan oleh Wina Sanjaya adalah bagaimana merancang strategi yang sesuai dengan tujuan dan kompetensi yang akan dicapai, karena tidak semua tujuan bisa dicapai oleh strategi tertentu (Wina, 2006:xiv). Sekolah Dasar Negeri 3 Pekanbaru, pelajaran Bahasa Indonesia telah diajarkan pada siswa dan berusaha meningkatkan aktivitas belajar siswa. Adapun usaha yang telah dilakukan oleh guru tersebut dapat dikemukakan sebagai berikut:1. Pelaksanaan pelajaran telah dilaksanakan sesuai dengan jadwal yang telah ditentukan. 2 . Membuat Rencana Pelaksanaan Pembelajaran (RPP). 3. Menyampaikan materi pelajaran melalui metode ceramah dan tanya jawab. 4. Memberikan latihan-latihan. Walaupun guru telah berusaha, namun aktivitas belajar siswa khususnya mata pelajaran bahasa Indonesia masih tergolong rendah. Melalui penelitian ini penulis meningkatkan aktivitas belajar siswa dengan menerapkan model pembelajaran pertemuan kelas.

Model pembelajaran pertemuan kelas adalah model pembelajaran yang ditujukan untuk membangun suatu kelompok sosial yang saling menyayangi, saling menghargai, mempunyai disiplin diri, dan komitmen untuk berperilaku positif (Hamzah, 2008:23). Model pembelajaran pertemuan kelas akan berhasil diterapkan jika seorang guru itu mampu melaksanakannya dengan baik. Sehingga siswa berantusias untuk mengikuti pelajaran yang disampaikan oleh guru dan menjadikan siswa terlibat aktif dalam proses pembelajaran yang berlangsung. Dengan demikian, aktivitas belajar siswa didalam kelas akan meningkat. Berdasarkan kenyataan itulah, penulis termotivasi untuk meneliti dengan judul: Meningkatkan Aktivitas Belajar Bahasa Indonesia Melalui Model Pembelajaran Pertemuan Kelas Siswa Kelas V SD Negeri 3 Pekanbaru.

\section{METODOLOGI}

Penelitian ini pada Bulan April 2013. Adapun tempat penelitian ini dilaksanakan di Sekolah Dasar Negeri 3 Pekanbaru. Subjek penelitian ini adalah guru Bahasa Indonesia dan siswa yang berada di kelas V SD Negeri 3 Pekanbaru.Objek penelitian ini adalah meningkatkan aktivitas belajar Bahasa Indonesia melalui model pembelajaran pertemuan kelas di SD Negeri 3 Pekanbaru.

Penelitian ini adalah penelitian tindakan kelas (PTK). Model penelitian tindakan kelas (PTK) yang peneliti gunakan adalah model Kemmis dan Mc Taggart. Adapun model PTK yang dimaksud menggambarkan adanya empat langkah dan pengulangannya. Adapun keempat langkah tersebut meliputi: perencanaan, aksi/tindakan, observasi dan refleksi (Suharsimi, 2010:37). Keempat langkah tersebut merupakan satu siklus atau putaran., artinya sesudah langkah ke-4, lalu kembali ke-1 dan seterusnya. Meskipun sifatnya berbeda, langkah ke-2 dan ke-3 dilakukan secara bersamaan jika pelaksana dan pengamat berbeda. Jika pelaksana juga pengamat, mungkin pengamatan dilakukan sesudah pelaksanaan, dengan cara mengingat-ingat apa yang sudah terjadi.

Teknik pengumpulan data yang digunakan Observasi untuk mengamati aktivitas guru selama pembelajaran dengan penerapan model pembelajaran pertemuan kelas dan untuk mengamati aktivitas belajar siswa pada mata pelajaran bahasa Indonesia selama penerapan model pembelajaran pertemuan kelas. Dan menggunakan Dokumentasi dengan mencari informasi mengenai profil sekolah, keadaan guru, keadaan siswa, saranan dan prasarana, serta kurikulum yang digunakan. 
Teknik analis data dalam penelitian ini pada aktivitas guru Setelah data terkumpul melalui observasi, data tersebut diolah dengan menggunakan rumus persentase (Anas, 2004:43)

$$
P=\frac{\mathrm{F}}{\mathrm{N}} \times 100 \%
$$

\section{Keterangan:}

$\mathrm{F} \quad=$ Frekuensi aktivitas guru

$\mathrm{N}=$ Skor maksimal aktivitas guru

$\mathrm{P} \quad=$ Angka persentase

$100 \%=$ Bilangan tetap

Keberhasilan guru dengan penerapan model pembelajaran pertemuan kelas dikatakan berhasil apabila mencapai interval 80\% - 89\% dengan kategori baik, hal ini sesuai dengan kategori berikut:

\section{Tabel 1. Kategori aktivitas guru}

\begin{tabular}{cc}
\hline Interval & Kategori \\
\hline $90-100$ & Baik Sekali \\
$80-89$ & Baik \\
$70-79$ & Cukup \\
$60-69$ & Kurang \\
$<60$ & Sangat Kurang \\
\hline
\end{tabular}

Keberhasilan guru dengan penerapan model pembelajaran pertemuan kelas dikatakan berhasil apabila mencapai interval 80\% - 89\% dengan kategori baik (Tim Pustaka, 2008:416).

Pada aktivitas siswa Keberhasilan siswa Aktivitas siswa selama kegiatan belajar mengajar yang dibukukan pada observasi dengan rumus:

$P=\frac{\mathrm{F}}{\mathrm{N}} \times 100 \%$

Keterangan:

$\mathrm{F} \quad=$ Frekuensi aktivitas siswa

$\mathrm{N} \quad=$ Skor maksimal aktivitas siswa

$\mathrm{P} \quad=$ Angka persentase

$100 \%=$ Bilangan tetap

Keberhasilan siswa dengan penerapan model pembelajaran pertemuan kelas dikatakan berhasil apabila mencapai interval 75\% - 84\% dengan kategori baik, hal ini sesuai dengan kategori berikut: 
Tabel 2. Kategori aktivitas siswa

\begin{tabular}{cc}
\hline Interval & Kategori \\
\hline $85-100$ & Baik Sekali \\
$75-84$ & Baik \\
$65-74$ & Cukup \\
$45-64$ & Kurang \\
$0-44$ & Sangat Kurang \\
\hline
\end{tabular}

\section{HASIL DAN PEMBAHASAN}

\section{Aktivitas Guru}

Berdasarkan hasil pengamatan aktivitas guru pada siklus I, diketahui berada pada kategori "kurang", karena skor 67 berada pada rentang 60 - 69. Sedangkan pada siklus II aktivitas guru meningkat dengan kategori "baik", dengan skor nilai 83 berada pada rentang 80 - 89 Perbandingan skor nilai aktivitas guru pada siklus I dan siklus II dapat dilihat pada tabel berikut:

\section{Tabel 3.}

\section{Rekapitulasi Aktivitas Guru Pada Siklus I dan Siklus II}

\begin{tabular}{|c|c|c|c|c|}
\hline \multirow{2}{*}{ Aktivitas Yang Diamati } & \multicolumn{2}{|c|}{ Siklus I } & \multicolumn{2}{|c|}{ Siklus II } \\
\hline & $\mathbf{Y a}$ & Tidak & Ya & Tidak \\
\hline $\begin{array}{l}\text { Guru membangun suatu kualitas hubungan yang kondusif, } \\
\text { hangat, personal dan terbuka. }\end{array}$ & $\sqrt{ }$ & - & $\sqrt{ }$ & - \\
\hline Guru menyampaikan permasalahan yang akan dibahas. & $\sqrt{ }$ & - & $\sqrt{ }$ & - \\
\hline $\begin{array}{l}\text { Guru meminta siswa memberikan penilaian terhadap } \\
\text { permasalahan yang disampaikan sebelumnya. }\end{array}$ & $\sqrt{ }$ & - & $\sqrt{ }$ & - \\
\hline $\begin{array}{l}\text { Guru meminta siswa mengidentifikasi alternatif tindakan } \\
\text { solusi untuk memecahkan masalah tersebut. }\end{array}$ & - & $\sqrt{ }$ & - & $\sqrt{ }$ \\
\hline $\begin{array}{l}\text { Guru meminta siswa untuk memberikan komitmen secara } \\
\text { bersama untuk mencari alternatif tindakan pada langkah } \\
\text { sebelumnya. }\end{array}$ & - & $\sqrt{ }$ & $\sqrt{ }$ & - \\
\hline $\begin{array}{l}\text { Guru meminta siswa untuk menjelaskan dan melaporkan } \\
\text { efektivitas dari alternatif-alternatif tindakan yang dilakukan }\end{array}$ & $\sqrt{ }$ & - & $\sqrt{ }$ & - \\
\hline Jumlah & 4 & 2 & 5 & 1 \\
\hline Persentase $(\%)$ & $66,70 \%$ & $33,30 \%$ & $83,30 \%$ & $16,70 \%$ \\
\hline
\end{tabular}

Selanjutnya perbandingan skor nilai aktivitas guru pada siklus I dan siklus II juga dapat dilihat pada gambar diagram berikut: 


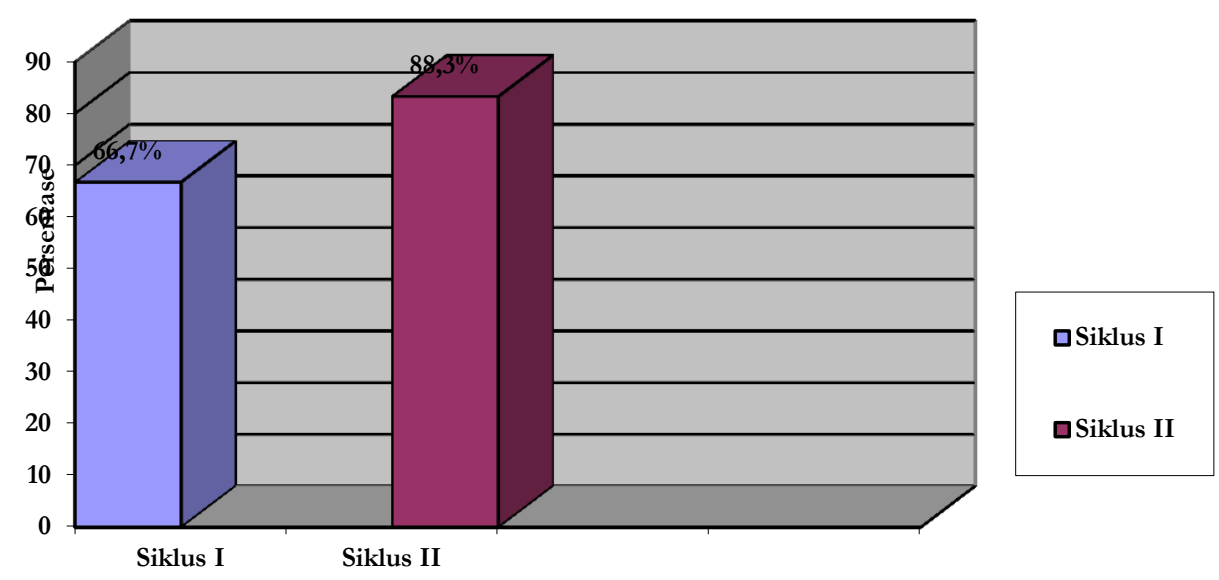

Hasil Pengamatan

\section{Gambar 1. Hasil Observasi Aktivitas Guru Pada Siklus I dan Siklus II}

\section{Aktivitas Belajar Siswa}

Sebagaimana diketahui aktivitas belajar Bahasa Indonesia pada siswa kelas V SD Negeri 3 Pekanbaru masih tergolong "kurang” karena skor 59 berada pada rentang 45 - 64 dengan rata-rata 58,9\%. Pada siklus I aktivitas belajar Bahasa Indonesia pada materi persoalan faktual pada siswa kelas V SD Negeri 3 Pekanbaru tergolong "cukup" karena skor 74 berada pada rentang 65 - 74 atau dengan rata-rata $73,8 \%$. Sedangkan pada siklus II aktivitas belajar Bahasa Indonesia meningkat dengan baik sekali dengan skor 89 berada pada rentang 85 - 100 atau dengan rata-rata 88,7\%. Untuk lebih jelas perbandingan aktivitas belajar Bahasa Indonesia sebelum tindakan, siklus I, dan siklus II dapat dilihat pada tabel berikut. 


\section{Tabel 4.}

Rekapitulasi Aktivitas Belajar Siswa Sebelum Tindakan, Siklus I, dan Siklus II

\begin{tabular}{|c|c|c|c|c|c|c|}
\hline \multirow[t]{2}{*}{ ASPEK YANG DIAMATI } & \multicolumn{2}{|c|}{$\begin{array}{l}\text { SEBELUM } \\
\text { TINDAKAN } \\
\text { Rata-rata }\end{array}$} & \multicolumn{2}{|c|}{$\begin{array}{l}\text { SIKLUS I } \\
\text { Rata-rata }\end{array}$} & \multicolumn{2}{|c|}{$\begin{array}{l}\text { SIKLUS II } \\
\text { Rata-rata }\end{array}$} \\
\hline & Jumlah & $\%$ & Jumlah & $\%$ & Jumlah & $\%$ \\
\hline $\begin{array}{l}\text { Siswa membentuk hubungan yang } \\
\text { kondusif, hangat, personal dan } \\
\text { terbuka. }\end{array}$ & 17 & $60,70 \%$ & 23 & $82,10 \%$ & 24 & $85,70 \%$ \\
\hline $\begin{array}{ll}\text { Siswa mendengarkan penjelasan } & \text { guru } \\
\text { tentang permasalahan } & \text { yang } \\
\text { disampaikan. } & \end{array}$ & 18 & $64,30 \%$ & 20 & $71,40 \%$ & 26 & $92,90 \%$ \\
\hline $\begin{array}{l}\text { Siswa memberikan penilaian terhadap } \\
\text { permasalahan yang disampaikan oleh } \\
\text { guru. }\end{array}$ & 15 & $53,60 \%$ & 21 & $75 \%$ & 24 & $85,70 \%$ \\
\hline $\begin{array}{l}\text { Siswa mengidentifikasi alternatif } \\
\text { tindakan solusi untuk memecahkan } \\
\text { masalah tersebut }\end{array}$ & 14 & $50 \%$ & 19 & $67,90 \%$ & 27 & 96,4 \\
\hline $\begin{array}{l}\text { Siswa memberikan komitmen secara } \\
\text { bersama untuk mencari alternatif } \\
\text { tindakan pada langkah sebelumnya }\end{array}$ & 18 & $64,30 \%$ & 18 & $64,30 \%$ & 22 & $78,60 \%$ \\
\hline $\begin{array}{l}\text { Siswa menjelaskan dan melaporkan } \\
\text { efektivitas dari alternatif-alternatif } \\
\text { tindakan yang dilakukan. }\end{array}$ & 17 & $60,70 \%$ & 18 & $64,30 \%$ & 26 & $92,90 \%$ \\
\hline Jumlah/ Persentase & 99 & $58,90 \%$ & 124 & $73,80 \%$ & 149 & $88,70 \%$ \\
\hline
\end{tabular}

Selanjutnya perbandingan aktivitas belajar Bahasa Indonesia siswa sebelum tindakan, siklus I, dan siklus II juga dapat dilihat pada gambar grafik berikut. 


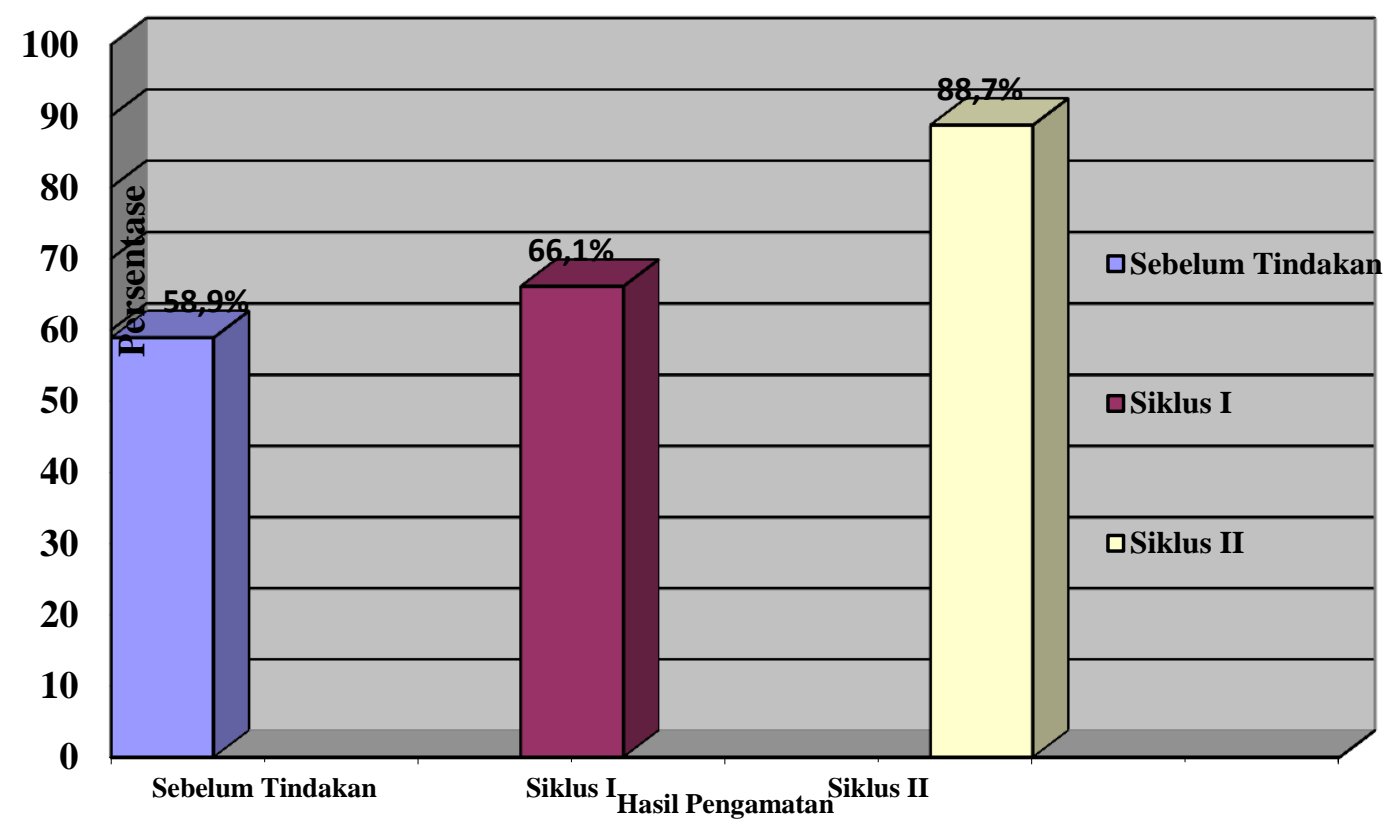

Gambar 2.

\section{Hasil Observasi Aktivitas Siswa Sebelum Tindakan, Siklus I, dan Siklus II}

Setelah melihat rekapitulasi aktivitas belajar Bahasa Indonesia pada sebelum tindakan, materi persoalan faktual dan materi drama pendek siswa kelas V SD Negeri 3 Pekanbaru dan gambar grafik diatas, dapat diketahui bahwa keberhasilan siswa telah mencapai indikator keberhasilan yang di tetapkan yaitu pada materi drama pendek terdapat pada interval 75\% - 84\%, dengan rata-rata 88,7\% kategori baik sekali. Untuk itu, peneliti sekaligus sebagai guru tidak perlu melakukan siklus berikutnya, karena sudah jelas aktivitas belajar Bahasa Indonesia pada materi drama pendek pada siswa kelas V SD Negeri 3 Pekanbaru yang diperoleh meningkat.

\section{KESIMPULAN}

Berdasarkan hasil pembahasan dan analisis peneliti maka dapat disimpulkan bahwa melalui model pembelajaran pertemuan kelas, aktivitas belajar bahasa Indonesia siswa kelas V SD Negeri 3 Pekanbaru dapat ditingkatkan dan menjadi lebih baik jika dibandingkan dengan sebelum diterapkannya strategi pembelajaran tersebut.

Hal ini ini terlihat pada aktivitas belajar siswa sebelum tindakan tergolong kurang yaitu memperoleh rata-rata persentase sebesar 58,9\% siswa yang aktif. Namun setelah diterapkannya model pembelajaran tersebut pada siklus I, aktivitas belajar siswa meningkat meningkat menjadi 66,1\%. Kemudian peneliti melanjutkan tindakan pada siklus II dan mencapai indikator keberhasilan yaitu meningkat menjadi baik sekali dengan rata-rata persentase $88,7 \%$.

\section{REFERENSI}

Ahmad, Rohani dkk. 2004. Pengelolaan Pengajaran, Jakarta: Rineka Cipta.

Anas, Sudijono. 2004. Pengantar Statistik Pendidikan Jakarta: Raja Gravindo Persada. 
Aunurrahman. 2009. Belajar dan Pembelajaran, Bandung: Alfabeta.

Dasim, Budimansyah. 2009. PAKEM Pembelajaran Aktif, Kreatif, Efektif, dan Menyenangkan Bandung: PT. Genesindo.

Departemen Pendidikan Nasional. 2007. Kamus Besar Bahasa Indonesia, Jakarta: Balai Pustaka.

Hamzah B, Uno. 2008. Model Pembelajaran Menciptakan Proses Belajar Mengajar yang Kreatif dan Efektif, Jakarta: Bumi Aksara.

Hartono. 2008. PAIKEM Pembelajaran Aktif, Inofatif, Kreatif, Efektif, dan Menyenangkan, Pekanbaru: Zanafa.

Hisam, Zaini. 2007. Strategi Pembelajaran Aktif, Yogyakarta: CTSD.

J.J Hasibuan. 2009. Proses Belajar Mengajar, Bandung: PT. Remaja Rosdakarya.

Martimis, Yamin. 2007. Kiat Membelajarkan Siswa, Jakarta: Gaung PersadaPress.

Roestiyah, N.K. 1989. Didaktik Metodik Jakarta: PT. Bina Aksara.

Silbermen. 2009. Active Learning 101 Cara Belajar Siswa Aktif, Yogyakarta: Nusamedia.

Slameto. 2010. Belajar dan Faktor-faktor yang Mempengaruhinya, Jakarta: Rineka Cipta.

Suharsimi, Arikunto. 2010. Prosedur Peneltian Suatu Pendekatan Paraktik, Jakarta: Rineka Cipta.

Syaiful Bahri Djamarah. 2006. Strategi Belajar Mengajar, Jakarta: Rineka Cipta.

S. Nasution. 2010. Didaktik Asas-asas Mengaja,r Jakarta: Bumi Aksara.

Tim Pustaka Yustisia. 2008. Panduan Lengkap KTSP (Kurikulum Tingkat Satuan Pendidikan), Yogyakarta: Pustaka Yustisia.

Wina, Sanjaya. 2006. Strategi Pembelajaran Berorientasi Standar Proses Pendidikan, Bandung: Kencana. 